\title{
PENILAIAN TAMAN WISATA ALAM SITU GUNUNG SUKABUMI: PENERAPAN TCM
}

\author{
Tatan Sukwika ${ }^{1}$, Fitra Rahmatulloh ${ }^{2}$ \\ ${ }^{1}$ Program Studi Teknik Lingkungan, Fakultas Teknik, Universitas Sahid Jakarta \\ tatan.swk@gmail.com \\ ${ }^{2}$ Program Studi Teknik Lingkungan, Fakultas Teknik, Universitas Sahid Jakarta \\ fitrarahmatullh@gmail.com
}

\begin{abstract}
ABSTRAK
Pengembangan dan pengelolaan kawasan wisata alam diperlukan nilai ekonomi lingkungan yang terdapat pada suatu kawasan pariwisata. Pembangunan wisata baru dapat meningkatkan nilai ekonomi suatu kawasan wisata. Nilai ekonomi lingkungan dapat menjadi acuan dalam pembangunan berkelanjutan. Tujuan penelitian menentukan nilai lingkungan dan faktor intensitas kunjungan wisatawan. Metode yang digunakan untuk penentuan nilai lingkungan adalah metode travel cost. Pengambilan data lapangan digunakan kuesioner dan wawancara responden. Hasil penelitian secara simultan menunjukkan terdapat pengaruh intensitas pengunjung terhadap faktor waktu tempuh, tingkat pendidikan, umur, dan tingkat pendapatan. Kesimpulannya biaya kunjungan wisata terbesar adalah biaya transportasi, nilai ekonomi kawasan taman wisata alam (TWA) Situ Gunung melampaui Rp200 miliar dan kesediaan membayar (WTP) pengunjung masih menyisakan $62,25 \%$ nilai ekonomi yang didapatkan dari total ekonomi. Penelitian lanjutan direkomendasikan fokus pada daya dukung lingkungan untuk melihat kegiatan pariwisata di kawasan TWA Situ Gunung Sukabumi untuk menunjang data TCM.
\end{abstract}

Kata kunci: metode biaya perjalanan, pariwisata, situ gunung Sukabumi, WTP

\begin{abstract}
The development and management of natural tourism areas should contain environmental economic value in it. The new development can increase the economic value of that tourism area. Environmental economic value can be a reference for sustainable development. The purpose of this study was to obtain environmental values and to determine the tourist visit intensity factor. Travel cost method was used in obtaining the environmental value. Retrieval of field data used questionnaires and interview respondents. The results of the research simultaneously showed that there was an effect on visitor intensity on the factors of travel time, education level, age, and income level. In conclusion, the biggest cost of tourist visits is the cost of transportation, the economic value of the Situ Gunung nature park (TWA) area exceeds Rp 200 billion and the willingness to pay (WTP) of visitors still leaves $62.25 \%$ of the economic value obtained from the total economy. Further research is recommended to focus on the carrying capacity of the environment to see tourism activities in the TWA Situ Gunung Sukabumi area to support TCM data.
\end{abstract}

Keywords: travel cost method, tourism, situ gunung Sukabumi, WTP

ISSN: 2355-6587, e-ISSN: 2528-2220

http://ejournal.bsi.ac.id/ejurnal/index.php/jp 


\section{PENDAHULUAN}

Indonesia mempunyai ragam budaya dan alam yang merupakan potensi daya tarik wisata. Pengembangan pariwisata di Indonesia sedang ditingkatkan. Pemanfaatan sumber daya alam dan lingkungan diantaranya adalah pariwisata Kegiatan pariwisata perlu diawasi dalam pelaksanaannya. Menciptakan hubungan yang harmonis antara penduduk lokal, pengunjung, warisan budaya dan lingkungan dapat menciptakan pariwisata berkelanjutan (Kemenpar, 2018).

Pengembangan pariwisata yang berbasis alam perlu dilakukan dengan tepat. Untuk melakukan pembangunan berkelanjutan dengan tepat, diperlukannya nilai ekonomi lingkungan sebagai acuan pengembangan. Nilai tersebut bisa didapatkan dengan melakukan valuasi ekonomi. Untuk tempat pariwisata, nilai ekonomi lingkungan dengan valuasi ekonomi dengan metode biaya perjalanan. Produk wisata yang dinikmati dari sumberdaya alam dan lingkungan (SDAL) baik berupa nilai pasar dan non-pasar, secara kuantitatif, dapat dinilai menggunakan metode penilaian ekonomi. Metode penilaian ekonomi dapat diterapkan pada dua macam, yaitu (Pegas \& Castley, 2014; Suparmoko et al., 2014; Yoeti, 2008): (a) Menilai aset atau kekayaan alam suatu Negara atau suatu daerah yang kemudian dinyatakan dalam neraca sumber daya alam dan lingkungan; dan (b) Menilai dampak suatu kegiatan terhadap aset/kekayaan alam baik yang bersifat positif (manfaat) dan negatif (beban atau biaya).

Travel Cost Method atau TCM sering digunakan untuk menganalisis permintaan terhadap wisata di alam terbuka. TCM tidak bisa digunakan sebagai asumsi dasar dalam penilaian sumber daya, jika (Fauzi, 2004; Jantzen, 2006; Suparmoko, 2006; Yoeti, 2008): (a) penentuan proxy atas harga rekreasi menggunakan biaya perjalanan dan biaya waktu; (b) waktu perjalanan bersifat netral, sehingga tidak ditemukan hasil baik secara utilitas maupun disutilitas; dan (c) biaya perjalanan bersifat perjalanan tunggal atau bukan multiple travel.
Persepsi masyarakat bisa dijadikan dalam menentukan nilai dari ekowisata serta SDAL, sehingga bisa didapatkan nilai ekonomi pada suatu kawasan yang sesuai degan prinsip dari penilaian ekonomi. Salah satu metode yang digunakan dalam melakukan penilaian ekonomi lingkungan adalah dengan metode biaya perjalanan (travel cost method/TCM) (Choe \& Fesenmaier, 2016; Gómez-Baggethun \& Ruiz-Pérez, 2011; Limaei et al., 2014; Suparmoko et al., 2014).

Penilaian ekonomi adalah usaha penilaian potensi keseluruhan maupun sebagian dari pemanfaatan SDAL untuk mendapatkan nilai ekonomi lingkungannya. Adapun nilai yang diperoleh berupa nilai ekonomi total, nilai pemulihan dan nilai mitigasi dari kerusakan/pencemaran (Fesenmaier \& Xiang, 2017; Gretzel et al., 2015; Mayer, 2014; Pegas \& Castley, 2014).

Nilai ekonomi SDAL diartikan sebagai pengukuran total maksimum seseorang dalam kesediaan membayar (willingness to pay/WTP) barang dan jasa guna mendapatkan barang dan jasa lainnya. Konsep ini disebut WTP seseorang pada barang dan jasa yang dihasilkan. WTP diukur dalam bentuk kenaikan pendapatan sehingga seseorang menjadi berada dalam posisi indifferent terhadap perubahan exogenous. Perubahan exogenous ini akibat adanya perubahan harga (misalnya kelangkaan sumberdaya) atau karena perubahan kualitas sumberdaya. Dalam teori permintaan, konsep WTP berkaitan dengan konsep variasi kompensasi (CV) dan Ekivalen (EV). Jadi, WTP dapat juga diartikan sebagai jumlah maksimal seseorang mau membayar untuk menghindari terjadinya penurunan terhadap sesuatu (Fauzi, 2004; Jantzen, 2006; Suparmoko, 2006).

Pengembangan pariwisata dilakukan di berbagai daerah, salah satunya di TWA Situ Gunung kabupaten Sukabumi. Di kawasan tersebut telah memiliki 3 objek wisata yang dapat dinikmati yaitu, danau situ gunung, air terjun curug sawer, dan jembatan Suspension Bridge yang baru selesai terbangun pada tahun 2017 (Gambar 1). Penambahan daya tarik wisata 
berupa Suspension Bridge di TWA Situ Gunung menjadi pendorong nilai tambah ekonomi. Nilai ekonomi dapat dijadikan dasar melakukan valuasi ekonomi untuk pengembangan pariwisata yang berkelanjutan (Pegas \& Castley, 2014; Sukwika et al., 2018; Sukwika \& Kasih, 2020; Sukwika \& Putra, 2020). Didasarkan pertimbangan alasan tersebut maka perlu dievaluasi nilai ekonomi TWA Situ Gunung melalui pendekatan metode travel cost.

\section{KAJIAN LITERATUR Valuasi Ekonomi}

Produk wisata yang dinikmati dari SDAL baik berupa nilai pasar dan nonpasar, secara kuantitatif, dapat dinilai menggunakan metode valuasi ekonomi. Sesuai kebutuhannya, valuasi ekonomi diterapkan pada dua macam, yaitu (Pegas \& Castley, 2014; Suparmoko et al., 2014; Yoeti, 2008): (1) Menilai aset atau kekayaan alam suatu Negara atau suatu daerah yang kemudian dinyatakan dalam neraca sumber daya alam dan lingkungan; (2) Menilai dampak suatu kegiatan terhadap aset/kekayaan alam baik yang bersifat positif (manfaat) dan negatif (beban atau biaya).

Nilai sebuah barang dan jasa dapat dibedakan berdasarkan nilai penggunaannya (instrumental value) dan tanpa penggunaannya (non-use value) atau nilai yang terkandung di dalam SDAL itu (intrinsic value). Nilai instrumental dilihat dari kemampuan dalam kegunaan suatu barang dan jasa dalam memenuhi kebutuhan. Nilai intrinsik yang melekat pada lingkungan tersebut, misalkan manfaat hutan dalam menjaga kestabilan ekosistem di lingkungan tersebut. Selanjutnya, non-use value dibedakan menurut warisan dari generasi yang sebelumnya (bequest value) dan nilai keberadaannya saja (existence value). Misal, keberadaan sumber daya hutan yang dilestarikan dapat memenuhi kebutuhan rekreasi dan kesenangan yang lain (warisan) dan keberadaan hutan itu sendiri dapat memelihara biodiversitas (Ekayani et al., 2014; Kemenpar, 2018; Mayer, 2014; Pegas \& Castley, 2014)
Dengan mengidentifikasikan nilai dapat menghitung nilai ekonomi total (total economi value/TEV). Perhitungan TEV dapat digunakan metode pendekatan produktivitas, TCM, kontingensi, dan benefit transfer. Perhitungan NET mempunyai kelebihan yaitu dapat melihat nilai keseluruhan dari suatu ekosistem tetapi dibutuhkan waktu, tenaga, dan biaya lebih besar. Kesediaan membayar pengunjung untuk produk jasa lingkungan atau sumber daya alam adalah dasar dalam melakukan teknik penilaian ekonomi (Amelia, 2016; Jantzen, 2006; Suparmoko et al., 2014).

\section{Pariwisata}

Pariwisata merupakan kegiatan bepergian dalam waktu singkat atau temporer yang lakukan menuju tempat lain, dengan tujuan tidak bermaksud kerja atau untuk melakukan usaha mencari keuntungan secara ekonomi (business), tetapi untuk melakukan liburan. Ada beberapa faktor yang dapat didefinisikan sebagai pariwisata, yaitu (Fesenmaier \& Xiang, 2017; Yoeti, 2008): (1) Kegiatan yang bersifat temporer; (2) Kegiatan bepergian ke tempat lain; (3) Kegiatan yang berkaitan untuk liburan dan rekreasi dalam bentuk apapun; (4) Kegiatan menjadi sebagai konsumen di tempat yang dituju.

\section{Travel Cost Method}

TCM sering digunakan untuk menganalisis permintaan terhadap wisata di alam terbuka. Pada tahun 1931, konsep analisis sederhana ini diperkenalkan Harold Hotelling yang kemudian Metode ini pada tahun 1966 dikembangkan oleh Clawson dan Knetsch. Dimana, dipaparkan bahwa perilaku wisatawan yang diamati dapat digunakan untuk membuat kurva permintaan dan menentukan nilai dari SDAL. Pengamatan perilaku terhadap wisatawan juga dapat digunakan untuk mendapatkan nilai surplus konsumen dari SDAL yang tidak mempunyai pasar melalui kuesioner yang dipusatkan pada peningkatan biaya perjalanan sebagai pasar pengganti. Terdapat dua asumsi dalam 
konsep TCM (Fauzi, 2004; Jantzen, 2006; Suparmoko, 2006):

1. Asumsi 1, kunjungan ke tempat rekreasi alam dipengaruhi oleh biaya bepergian ke tempat rekreasi di mana perjalanan merupakan perjalanan tunggal. Fungsi permintaannya adalah:

$$
V_{i}=f\left(C_{i}, X 1_{i}, X 2_{i}, \ldots, X N_{i}\right)
$$

Dimana, $\mathrm{V} i=$ kunjungan oleh individu ke I; $\mathrm{Ci}=$ biaya kunjungan oleh individu ke I; $\mathrm{XN} i=$ variabel (faktor) lain yang relevan.

2. Asumsi 2, semua individu memberikan reaksi serupa terhadap peningkatan/ penurunan biaya perjalanan dan tarif masuk untuk mengunjungi suatu tempat rekreasi.

Metode TCM didasarkan pada biaya perjalanan dan waktu yang dikeluarkan terhadap kegiatan yang dilakukan di daerah wisata. Pada dasarnya harga masuk ke tempat wisata tidak dapat menggambarkan keseluruhan dari nilai wisata yang disajikan. Penggunaan metode TCM dapat menggambarkan secara keseluruhan nilai dari daya tarik wisata tersebut. Begitu juga. nilai surplus konsumen dapat tergambarkan dari perhitungan kurva permintaan didasarkan pada pemanfaatan tempat rekreasi tersebut secara aktual.

Pengeluaran waktu, uang, atau barang oleh individu untuk memperoleh keinginan produk barang atau jasa tertentu merupakan acuan untuk menentukan ukuran harga. Menganalisis permintaan terhadap daerah wisata merupakan cara untuk penilaian dengan metode biaya perjalanan. Total biaya perjalanan dibentuk oleh komponen seperti biaya transportasi, tiket masuk, konsumsi, akomodasi, dokumentasi, dan biaya lain-lain yang berkaitan dengan kegiatan rekreasi (Choe \& Fesenmaier, 2016; Djijono, 2002; Stienmetz \& Fesenmaier, 2013)

TCM tidak bisa digunakan sebagai asumsi dasar dalam penilaian sumber daya, jika (Fauzi, 2004; Jantzen, 2006; Suparmoko, 2006; Yoeti, 2008): (a) penentuan proxy atas harga rekreasi menggunakan biaya perjalanan dan biaya waktu; (b) waktu perjalanan bersifat netral, sehingga tidak ditemukan hasil baik secara utilitas maupun disutilitas; dan (c) biaya perjalanan bersifat perjalanan tunggal atau bukan multiple travel.

\section{METODE PENELITIAN}

Metode deskriptif digunakan untuk mendapatkan informasi dan data, sehingga masalah yang diangkat dalam penelitian ini dapat dicari jawabannya. Data telah dikumpulkan kemudian diolah secara kualitatif dan kuantitatif. Pendekatan deskriptif ini untuk mengukur nilai lingkungan dari kawasan TWA Situ Gunung yang merupakan bagian dari Kawasan konservasi Gunung Gede Pangrango.

Pengumpulan data bersumber pada data primer dan sekunder. Data primer dikumpulkan melalui observasi dan wawancara di lapangan, sedangkan data sekunder bersumber pada referensi seperti jurnal, buku, dan peraturan yang relevan. Pengambilan sampling menggunakan purposive sampling. Responden yang diambil merupakan wisatawan yang sedang berkunjung di kawasan Taman Wisata Alam Situ Gunung dan memiliki penghasilan.

\section{Metode Travel Cost Method}

Pada tahun 1931, konsep penilaian ini diperkenalkan Harold Hotelling yang kemudian metode ini pada tahun 1966 dikembangkan oleh Clawson dan Knetsch. Dimana, dipaparkan bahwa perilaku wisatawan yang diamati dapat digunakan untuk membuat kurva permintaan dan menentukan nilai dari SDAL. Pengamatan perilaku terhadap wisatawan juga dapat digunakan untuk mendapatkan nilai surplus konsumen dari SDAL yang tidak mempunyai pasar melalui kuesioner yang dipusatkan pada peningkatan biaya perjalanan sebagai pasar pengganti. Terdapat dua asumsi dalam konsep TCM (Fauzi, 2004; Jantzen, 2006; Suparmoko, 2006): (a) Asumsi 1, kunjungan ke tempat rekreasi alam dipengaruhi oleh biaya bepergian ke tempat rekreasi di mana perjalanan merupakan perjalanan tunggal. Fungsi permintaannya:

$$
V_{i}=f\left(C_{i}, X 1_{i}, X 2_{i}, \ldots, X N_{i}\right)
$$

dimana, $\mathrm{V} i=$ kunjungan oleh individu ke $I$; 
$\mathrm{Ci}=$ biaya kunjungan oleh individu ke $\mathrm{I}$; $\mathrm{XN} i=$ variabel (faktor) lain yang relevan; dan (b) Asumsi 2, semua individu memberikan reaksi serupa terhadap peningkatan/penurunan biaya perjalanan dan tarif masuk untuk mengunjungi suatu tempat rekreasi.

Metode TCM didasarkan pada biaya perjalanan dan waktu yang dikeluarkan terhadap kegiatan yang dilakukan di daerah wisata. Pada dasarnya harga masuk ke tempat wisata tidak dapat menggambarkan keseluruhan dari nilai wisata yang disajikan. Penggunaan metode TCM dapat menggambarkan secara keseluruhan nilai dari daya tarik wisata tersebut. Begitu juga. nilai surplus konsumen dapat tergambarkan dari perhitungan kurva permintaan didasarkan pada pemanfaatan tempat rekreasi tersebut secara aktual.

Pengeluaran waktu, uang, atau barang oleh individu untuk memperoleh keinginan produk barang atau jasa tertentu merupakan acuan untuk menentukan ukuran harga. Menganalisis permintaan terhadap daerah wisata merupakan cara untuk penilaian dengan metode biaya perjalanan. Total biaya perjalanan dibentuk oleh komponen seperti biaya transportasi, tiket masuk, konsumsi, akomodasi, dokumentasi, dan biaya lain-lain yang berkaitan dengan kegiatan rekreasi (Choe \& Fesenmaier, 2016; Djijono, 2002; Stienmetz \& Fesenmaier, 2013; Sukwika \& Kasih, 2020)

Dengan analisis linier berganda, data penelitian yang diperoleh diolah untuk mengetahui faktor-faktor yang mempengaruhi intensitas kunjungan. Proses uji hipotesis menggunakan uji-t dan uji-f dengan tingkat ketelitian yaitu 5\% atau 0,05. Alat yang diguakan adalah SPSS 22. Model persamaan regresi berganda sebagai berikut:

$$
Y=a+b_{1} X_{1}+b_{2} X_{2}+\ldots+b_{n} X_{n}
$$

Keterangan:

$\mathrm{Y}=$ intensitas kunjungan dari responden

$\mathrm{X} 1$ = lama perjalanan

$\mathrm{X} 2$ = tingkat pendidikan

$\mathrm{X} 3$ = umur

$\mathrm{X} 4$ = tingkat pendapatan

$\mathrm{X} 5$ = biaya perjalanan
$\mathrm{A}=$ intercept $\mathrm{konstanta}$

b1;b2;bn = Koefisien regresi $\mathrm{X}$

Untuk mengetahui nilai

lingkungan, dilakukan pengambilan data dari responden berupa biaya perjalanan yang dilakukan kepada wisatawan. Berikut adalah rumus biaya perjalanan:

$$
B P T=B K+B T+B D+B P
$$

Keterangan :

BPT = biaya perjalanan total

BK = biaya konsumsi

BT = biaya transportasi

$\mathrm{BD}=$ biaya dokumentasi

$\mathrm{BP}=$ biaya parkir

Pengukuran surplus konsumen dilakukan setelah diperoleh persamaan fungsi permintaan. Fungsi permintaan merupakan proxy dari nilai WTP terhadap kawasan wisata. Surplus konsumen pada fungsi permintaan bersifat linear, dan dapat diukur melalui formula:

$$
W T P \cong \mathrm{CS}=\frac{N^{2}}{2 b_{5}}
$$

Keterangan:

$\mathrm{CS}=$ surplus konsumen

$\mathrm{X}=$ jumlah kunjungan responden (kali/tahun)

$\mathrm{b}_{5} \quad=$ koefisien biaya perjalanan pada persamaan

$\mathrm{N}=$ intensitas kunjungan

$$
\mathrm{cS}^{\prime}=\frac{\operatorname{cs} / 2 x}{n}
$$

Keterangan:

$\mathrm{CS}^{\prime}$ = surplus konsumen/individu/

kunjungan

$\mathrm{n} \quad=$ jumlah responden

$$
\mathrm{EV}=\operatorname{cS}^{b} x K
$$

Keterangan:

$\mathrm{EV}$ = nilai ekonomi per tahun

$\mathrm{K}$ = estimasi kunjungan per tahun 2020

\section{PEMBAHASAN}

\section{Faktor Pengaruh Kunjungan Wisatawan}

Pada penelitian ini faktor yang mempengaruhi intensitas pengunjung di uji dengan cara regresi linier. Faktor-faktor yang diuji adalah waktu tempuh, tingkat pendidikan, umur, tingkat pendapatan, dan biaya perjalanan. Berdasarkan pengujian

ISSN: 2355-6587, e-ISSN: 2528-2220

http://ejournal.bsi.ac.id/ejurnal/index.php/jp 
data dari 100 orang responden dengan menggunakan lima variable independent dengan nilai probabilitas 0,05 maka didapatkan $\mathrm{t}$ tabel sebesar 1,66105 dan $\mathrm{F}$ tabel sebesar 2,31.

Pada persamaan regresi didapatkan bahwa konstanta sebesar 2,821 artinya jika tidak ada pengaruh jarak tempuh, tingkat pendidikan, umur, tingkat pendapatan, dan biaya perjalanan maka intensitas kunjungan akan naik sebesar 2,821. Nilai $F$ tabel yang diperoleh sebesar 2,31. Dari Tabel 2, terlihat nilai $\mathrm{F}$ adalah 4,665 lebih besar dibandingkan dengan $F$ tabel. Sehingga dapat dinyatakan bahwa tolak H0. Waktu tempuh, tingkat pendidikan, umur, tingkat pendapatan dan biaya perjalanan secara simultan berpengaruh secara signifikan terhadap intensitas kunjungan wisata.

Variabel waktu tempuh yaitu sebesar - 0,674 , artinya jika jarak tempuh semakin jauh maka berpengaruh terhadap penurunan kunjungan wisata sebesar 0,674 dengan asumsi variabel lain tetap. Waktu tempuh memiliki nilai t 3,930 dengan nilai probabilitas signifikan sebesar 0,000 (nilai $\mathrm{t}$ hitung > t tabel) sehingga tolak $\mathrm{H} 0$. Artinya, terdapat pengaruh signifikan antara waktu tempuh dan intensitas kunjungan wisatawan. Variabel waktu tempuh perjalanan berpengaruh signifikan secara parsial terhadap intensitas kunjungan wisatawan. Keterbatasan waktu menyulitkan wisatawan untuk ke tempat wisata dengan membutuhkan waktu yang lebih lama. Waktu tempuh perjalanan dapat dipengaruhi juga dengan dari tingkat kepadatan lalu lintas yang dilewati oleh wisatawan menuju kawasan wisata. Wisatawan relatif menyukai perjalanan ke tempat dengan waktu tempat yang lebih cepat dibandingkan dengan lama, karena dengan waktu tempat yang lebih cepat maka akan lebih lama di tempat wisata. Dalam penelitian Zulpikar et al. (2017) dan Sukwika dan Kasih (2020) ada kecenderungan bahwa kunjungan wisatawan yang tempat tinggalnya lebih dekat ke lokasi wisata jumlahnya lebih banyak dibandingkan wisatawan yang datang dari tempat yang lebih jauh.
Variabel tingkat pendidikan memiliki nilai 0,179 artinya akan memiliki kenaikan intensitas kunjungan sebesar 0,179 jika terjadi kenaikan tingkat pendidikan dengan asumsi variabel lain tetap. Tingkat pendidikan memiliki nilai $\mathrm{t}$ 0,670 dengan nilai probabilitas signifikan sebesar 0,505 (nilai $\mathrm{t}$ hitung $<\mathrm{t}$ tabel) sehingga terima H0. Berarti tidak terdapat pengaruh signifikan antara tingkat pendidikan dan intensitas kunjungan wisatawan. Variabel tingkat pendidikan tidak berpengaruh signifikan secara parsial terhadap intensitas kunjungan wisatawan. Pada kawasan TWA Situ Gunung, wisatawan yang berkunjung sebagian besar merupakan kegiatan wisata sehingga semua kalangan dari segi tingkat pendidikan dapat berkunjung ke tempat wisata ini. Hasil uji regresi selengkapnya disajikan pada Tabel 1.

Variabel umur memiliki nilai artinya 0,037 akan memiliki kenaikan intensitas kunjungan sebesar 0,037 jika terjadi umur semakin bertambah dengan asumsi variabel lain tetap Umur memiliki nilai $\mathrm{t}$ 0,185 dengan nilai probabilitas signifikan sebesar 0,853 (nilai $\mathrm{t}$ hitung $<\mathrm{t}$ tabel) sehingga terima H0. Artinya, tidak ada pengaruh signifikan antara Umur dan intensitas kunjungan wisatawan, begitunya secara parsial. Hal ini disebabkan karena penyuka tempat wisata alam bisa dari semua kalangan, mulai dari anak-anak, dewasa, hingga lanjut usia. Bahkan, memilik karakteristik yang cocok untuk kegiatan bersama, seperti dengan teman, keluarga, maupun rombongan. Sehingga umur wisatawan dalam kawasan tersebut sangat heterogen.

Variabel tingkat pendapatan memiliki nilai 0,186 artinya akan memiliki kenaikan intensitas kunjungan sebesar 0,186 jika terjadi kenaikan tingkat pendapatan dengan asumsi variabel lain tetap. Tingkat pendapatan memiliki nilai $\mathrm{t}$ 1,184 dengan nilai probabilitas signifikan sebesar 0,239. Nilai t hitung lebih kecil yaitu 1,184 dibandingkan dengan $t$ tabel yaitu 1,661 sehingga terima $\mathrm{H} 0$. 


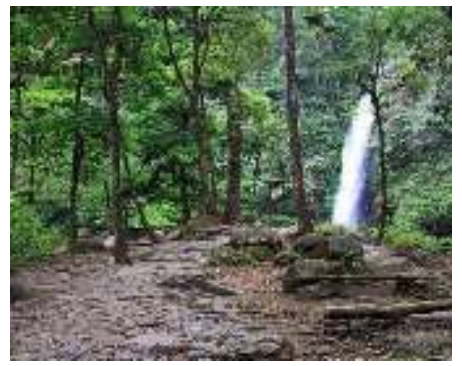

(a)

Air Terjun Curug Sawer

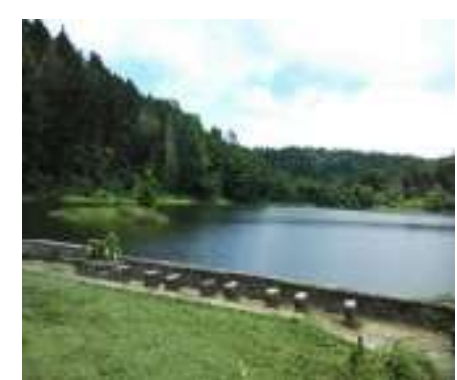

(b)

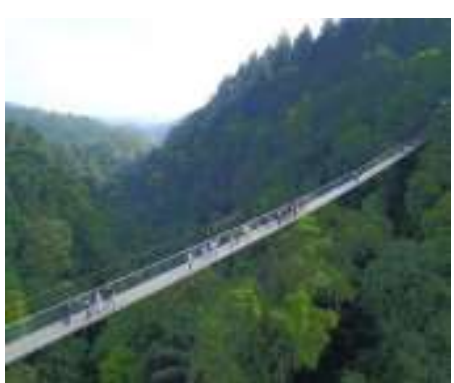

(c)

Gambar 1. Daya Tarik Kawasan TWA Situ Gunung Sukabumi Jawa Barat

Sumber: Data Penelitian, 2020

Tabel 1. Hasil Uji Regresi

\begin{tabular}{|c|c|c|c|c|c|}
\hline \multirow[t]{2}{*}{ Coefficients $^{a}$} & \multicolumn{2}{|c|}{$\begin{array}{c}\text { Unstandardized } \\
\text { Coefficients }\end{array}$} & \multirow{2}{*}{$\begin{array}{c}\begin{array}{c}\text { Standardized } \\
\text { Coefficients }\end{array} \\
\text { Beta }\end{array}$} & \multirow{2}{*}{$\mathrm{T}$} & \multirow{2}{*}{ Sig. } \\
\hline & B & $\begin{array}{l}\text { Std. } \\
\text { Error }\end{array}$ & & & \\
\hline 1 (Constant) & 2,821 & 0,977 & & 2,889 & 0,005 \\
\hline Waktu Tempuh & $-0,674$ & 0,172 & $-0,419$ & $-3,930$ & 0,000 \\
\hline Tingkat Pendidikan & 0,179 & 0,267 & 0,065 & 0,670 & 0,505 \\
\hline Umur & 0,037 & 0,202 & 0,018 & 0,185 & 0,853 \\
\hline Tingkat Pendapatan & 0,186 & 0,157 & 0,128 & 1,184 & 0,239 \\
\hline Biaya Perjalanan & $-1,698 \mathrm{E}-06$ & 0,000 & $-0,098$ & $-0,866$ & 0,389 \\
\hline
\end{tabular}

a. Dependen variabel: intensitas kunjungan

Sumber: Data Penelitian, 2020

Tabel 2. Hasil Uji Simultan (Uji F)

\begin{tabular}{llrrrrr}
\hline \multicolumn{1}{l}{ Anova } & Model & $\begin{array}{c}\text { Sum of } \\
\text { Squares }\end{array}$ & df & $\begin{array}{r}\text { Mean } \\
\text { Square }\end{array}$ & F & \multirow{2}{*}{ Sig. } \\
\hline 1 & Regression & 58.485 & 5 & 11.697 & 4.665 & $.001 \mathrm{~b}$ \\
\cline { 2 - 7 } & Residual & 235.705 & 94 & 2.507 & & \\
\cline { 2 - 7 } & Total & 294.190 & 99 & & & \\
\hline
\end{tabular}

a. Dependent variable: intensitas kunjungan

b. Predictors: biaya perjalanan, umur, tingkat pendidikan, waktu tempuh, tingkat pendapatan

Sumber: Data Penelitian, 2020

Tabel 3. Asumsi Kenaikan Tiket

\begin{tabular}{llllll}
\hline $\begin{array}{l}\text { Haraga } \\
\begin{array}{l}\text { Tiket } \\
(\mathrm{Rp})\end{array}\end{array}$ & $\begin{array}{l}\text { Nilai Total } \\
\text { Ekonomi (Rp) }\end{array}$ & $\begin{array}{l}\text { Total } \\
\text { Kunjungan }\end{array}$ & $\begin{array}{l}\text { Biaya Per- } \\
\text { jalanan per } \\
\text { Kunjungan } \\
(\mathrm{Rp})\end{array}$ & $\begin{array}{l}\text { Biaya } \\
\text { Perjalanan per } \\
\text { Tahun (Rp) }\end{array}$ & $\begin{array}{l}\text { Nilai Ekonomi } \\
\text { Tersisa (Rp) }\end{array}$ \\
\hline 18.500 & 204.273 .386 .470 & 332.010 & 228.000 & 75.698 .280 .000 & 128.575 .106 .470 \\
\hline 22.750 & 204.273 .386 .470 & 332.010 & 232.50 & 77.109 .322 .500 & 127.164 .063 .970 \\
\hline \multicolumn{5}{c}{ Sumber: Data primer diolah, 2020 } \\
\hline
\end{tabular}

Berarti tidak terdapat pengaruh signifikan antara tingkat pendidikan dan intensitas kunjungan wisatawan. Variabel tingkat pendapatan tidak berpengaruh signifikan secara parsial terhadap intensitas kunjungan wisatawan. Hal ini karena harga tiket masuk Rp18.500 masih dianggap murah oleh wisatawan yang berkunjung

ISSN: 2355-6587, e-ISSN: 2528-2220 
untuk menikmati jembatan Suspension Bridge yang menjadi salah satu daya tarik. Variabel biaya perjalanan memiliki nilai $1,698 \times 10^{-6}$ artinya akan memiliki penurunan intensitas kunjungan sebesar $1,698 \times 10^{-6}$ jika terjadi penambahan biaya sebesar Rp.1 dengan asumsi variabel lain tetap. Biaya perjalanan memiliki nilai $\mathrm{t}$ 0,866 dengan nilai probabilitas signifikan sebesar 0,239 (nilai $\mathrm{t}$ hitung $<\mathrm{t}$ tabel) sehingga terima H0. Berarti tidak terdapat pengaruh signifikan antara tingkat pendidikan dan intensitas kunjungan wisatawan. Variabel biaya perjalanan tidak berpengaruh signifikan secara parsial terhadap intensitas kunjungan wisatawan. Hal ini disebabkan karena viralnya kawasan ini dengan adanya pembangunan jembatan Suspension Bridge sehingga wisatawan tidak mempermasalahkan dengan biaya perjalanan yang dikeluarkan.

\section{Pendugaan Surplus Konsumen}

Nilai ekonomi rekreasi diperoleh melalui pendugaan jumlah pengunjung. Rata-rata peningkatan pengunjung sepanjang tahun 2014-2018 adalah 14,96\% (Tabel 4).

Estimasi kenaikan jumlah pengunjung dapat menggunakan rumus:

$Y_{20}=(1+a)^{Y 20-Y 18} \times Y_{18}$

$Y_{20}=(1+14,96 \%)^{2020-2018} \times 251.222$

$Y_{20}=332.010$

$\mathrm{Y}_{20}=$ Jumlah pengunjung tahun 2020

$\mathrm{Y}_{17}=$ Jumlah pengunjung tahun 2018

$\mathrm{a}=\%$ Pertumbuhan

Selanjutnya, nilai ekonomi lingkungan digunakan data biaya perjalanan dan jumlah kunjungan wisatawan. Rata-rata suplus konsumen perkunjungan adalah Rp615.263. Nilai surplus konsumen lebih tinggi dari ratarata biaya aktual yang dikeluarkan oleh pengujung yaitu sebesar Rp228.000. Dengan asumsi adanya pertumbuhan pengunjung di tahun 2020 yaitu menjadi 332.010 orang, maka didapatkan nilai ekonomi lingkungan sebesar Rp204,27 miliar (Tabel 3). Nilai ekonomi lingkungan yang tinggi ditemukan juga pada wisata Pantai Batu Karas (Zulpikar et al., 2017), TWA Gunung Halimun (Ekayani et al.,
2014), dan Mausoleh forest park (Limaei et al., 2014).

\begin{tabular}{ccrc}
\multicolumn{4}{c}{ Tabel 4. Pertumbuhan Pengunjung } \\
\hline Tahun & Jumlah & Selisih & $\begin{array}{c}\% \\
\text { Pertum- } \\
\text { buhan }\end{array}$ \\
\hline 2014 & 168.364 & & \\
2015 & 155.285 & -13.079 & $-7,77 \%$ \\
2016 & 162.184 & 6.899 & $4,44 \%$ \\
2017 & 144.118 & -18.066 & $-11,14 \%$ \\
2018 & 251.222 & 107.104 & $74,32 \%$ \\
\hline Rata-rata & 176.235 & 20.715 & $14,96 \%$ \\
\hline \multicolumn{4}{l}{ Sumber: Data diolah (B2TNG2P, 2019) }
\end{tabular}

Estimasi kenaikan jumlah pengunjung dapat menggunakan rumus :

$Y_{20}=(1+a)^{Y 20-Y 18} \times Y_{18}$

$Y_{20}=(1+14,96 \%)^{2020-2018} \times 251.222$

$Y_{20}=332.010$

$\mathrm{Y}_{20}=$ Jumlah pengunjung tahun 2020

$\mathrm{Y}_{17}=$ Jumlah pengunjung tahun 2018

$\mathrm{a}=\%$ Pertumbuhan

\section{Kesediaan Membayar}

Terdapat sekitar $7,5 \%$ responden beraggapan bahwa harga tiket masih tergolong murah, 32,5\% beranggapan mahal, dan $60 \%$ masih terjangkau. Diperoleh informasi dari wawancara bahwa pengunjung menunjukkan sikap kesediaan apabila ada kenaikan harga tiket. Data hasil analisis kesediaan membayar pengunjung disajikan pada Tabel 5.

Pada penelitian ini didapatkan kesediaan membayar Rp22.750. Kenaikan harga akan mendapatkan nilai manfaat lebih dari pengelolaan kawasan TWA Situ Gunung. Kenaikan harga berpengaruh terhadap biaya perjalanan wisatawan. Diasumsikan jika terjadi kenaikan harga dengan nilai ekonomi dan pengunjung tetap, maka pengelola mendapatkan nilai manfaat kawasan tersebut sebesar 0,69\% yaitu sekitar Rp1,41 miliar. Kenaikan harga ini masih menyisakan $62,25 \%$ nilai ekonomi yaitu sebesar Rp127,20 miliar yang masih bisa didapatkan. Hasil penelitian ini lebih kecil dibandingkan kesediaan membayar pengujung dengan TWA Pahawang Rp26.375 (Al-Khoiriah,

ISSN: 2355-6587, e-ISSN: 2528-2220

http://ejournal.bsi.ac.id/ejurnal/index.php/jp 
2017), wisata Gua Pindul Rp61.418 (Annisa \& Harini, 2017) dan TWA Gunung Pancar (Sukwika \& Kasih, 2020).

Mayoritas responden yaitu sebanyak 69 orang diketahui memilih bersedia membayar Rp20.000. Ada kecenderungan kesediaan pengunjung membayar tiket jika terjadi kenaikan rata-rata adalah Rp22.750 atau terjadi kenaikannya sebesar Rp3.375 dari harga tiket awal yaitu Rp18500. Pada kondisi ini ada kencenderungan dimana jika terjadi kenaikan harga tiket maka dimungkinkan ada perubahan pada konsumen surplus atau nilai manfaaat ekonomi.

Tabel 5. Kesediaan Membayar

\begin{tabular}{lcr}
\hline No. & $\begin{array}{c}\text { Harga Tiket } \\
(\mathrm{Rp})\end{array}$ & $\begin{array}{r}\text { Jumlah } \\
\text { Responden }\end{array}$ \\
\hline 1 & 10.000 & 0 \\
2 & 20.000 & 69 \\
3 & 25.000 & 18 \\
4 & 35.000 & 11 \\
\hline \multicolumn{2}{l}{ Rata-Rata } \\
Minimum & 22.750 \\
Maksimum & 20.000 \\
Median & 35.000 \\
\hline
\end{tabular}

Sumber: Data primer diolah, 2020

\section{PENUTUP}

\section{Kesimpulan}

Waktu tempuh menjadi faktor yang paling dipengaruhi oleh intensitas kunjungan. Biaya pengeluaran wisatawan lokal untuk perjalanan dan kunjungan berkisar antara Rp66.690-Rp224.400, dimana biaya kunjungan wisata terbesar adalah biaya transportasi dan waktu tempuh wisatawan ke lokasi wisata paling jauh adalah 5 jam. Kesediaan membayar pengunjung masih menyisakan 62,25\% nilai ekonomi yang didapatkan dari total ekonomi.

Perlu dilakukan penelitian lebih lanjut mengingat metode biaya perjalanan memiliki kelemahan, dimana TCM hanya mengasumsikan wisatawan sebagai tujuan tunggal. Oleh karena itu, sebagai penunjang TCM maka penelitian selanjutnya perlu difokuskan pada daya dukung lingkungan kegiatan pariwisata di kawasaan TWA Situ Gunung.

\section{REFERENSI}

Al-Khoiriah, R. (2017). Valuasi ekonomi dengan metode travel cost pada taman wisata pulau pahawang kabupaten Pesawaran. (Skripsi), Universitas Lampung, Lampung.

Amelia, D. (2016). Willingness to pay (WTP) masyarakat DIY terhadap obyek wisata kebun raya dan kebun binatang gembira loka. (Skripsi), Universitas Muhammdiyah Yogyakarta, Yogyakarta.

Annisa, T. M., \& Harini, R. (2017). Analisis kesediaan membayar (WTP) untuk mendukung ekowisata berkelanjutan di kawasn wisata gua pindul kabupaten Gunungkidul. Jurnal Bumi Indonesia, 6(4), 1-9.

B2TNG2P. (2019). Statistik balai besar taman nasional gunung gede pangrango tahun 2018. Bogor: Balai Besar Taman Nasional Gunung Gede Pangrango.

Choe, Y., \& Fesenmaier, D. (2016). The quantified traveler: Implications for designing tourism systems. Paper presented at the ENTER, Bilbao, Spain.

Djijono. (2002). Valuasi ekonomi menggunakan metode travel cost taman wisata hutan di taman wisata wan abdul rahman, propinsi Lampung. (Makalah Pengantar Falsafah Sains), Institut Pertanian Bogor, Bogor.

Ekayani, M., Nuva, Yasmin, R., Sinaga, F., \& Maaruf, L. O. M. (2014). Wisata alam taman nasional gunung halimun salak: Solusi kepentingan ekologi dan ekonomi. Jurnal Ilmu Pertanian Indonesia, 19(1), 29-37.

Fauzi, A. (2004). Ekonomi sumber daya alam dan lingkungan: Teori dan aplikasi. Jakarta: PT Gramedia Pustaka Utama.

Fesenmaier, D. R., \& Xiang, Z. (2017). Introduction to tourism design and design science in tourism. In D. R. Fesenmaier \& Z. Xiang (Eds.), Design science in tourism: Foundations of destination 
management (pp. 3-16). Cham: Springer International Publishing.

Gómez-Baggethun, E., \& Ruiz-Pérez, M. (2011). Economic valuation and the commodification of ecosystem services. Progress in Physical Geography, 35, 613-628.

Gretzel, U., Werthner, H., Koo, C., \& Lamsfus, C. (2015). Conceptual foundations for understanding smart tourism ecosystems. Computers in Human Behavior, 50, 558-563.

Jantzen, J. (2006). The economic value of natural and environmental resources. TME: Institute for Applied Environmental Economics.

Kemenpar. (2018). Rencana strategis 2018-2019 kementrian pariwisata. Jakarta: Kementrian Pariwisata.

Limaei, S. M., Ghesmati, H., Rashidi, R., \& Yamini, N. (2014). Economic evaluation of natural forest park using the travel cost method (case study; Masouleh forest park, north of Iran). Journal of Forest Science, 60(6), 254-261.

Mayer, M. (2014). Can nature-based tourism benefits compensate for the costs of national park? A study of the bavarian forest national park, Germany. Journal of Sustainable Tourism, 22(4), 561-583.

Pegas, F. V., \& Castley, J. G. (2014). Ecotourism as a conservation tool and its adoption by private protected areas in Brazil. Journal of Sustainable Tourism, 22(4), 604625.

Stienmetz, J. L., \& Fesenmaier, D. R. (2013). Traveling the network: A proposal for destination performance metrics. International Journal of Tourism Sciences, 13(2), 57-75.

Sukwika, T., Darusman, D., Kusmana, C., \& Nurrochmat, D. R. (2018). Skenario kebijakan pengelolaan hutan rakyat berkelanjutan di Kabupaten Bogor. Jurnal Pengelolaan Sumberdaya Alam dan Lingkungan, $\quad 8(2), \quad$ 207-215. doi:10.29244/jpsl.8.2.207-215

Sukwika, T., \& Kasih, H. (2020). Valuasi ekonomi taman wisata alam gunung pancar kabupaten Bogor. Jurnal Destinasi Pariwisata, 8(2), 285-290. doi:10.24843/JDEPAR.2020.v08.i02 .p17

Sukwika, T., \& Putra, H. (2020). Model of economic and environmental services value around industrial zone. Journal of System Dynamics, l(1), 26-32.

Suparmoko. (2006). Panduan dan analisis valuasi ekonomi sumberdaya alam dan lingkungan (konsep, metode perhitungan, dan aplikasi) (Kesatu ed.). Yogyakarta: BPFE.

Suparmoko, Sudirman, D., Setyarko, Y., \& Setyo, H. (2014). Valuasi ekonomi sumberdaya alam dan lingkungan (Kesatu ed.). Yogyakarta: BPFE.

Yoeti, O. A. (2008). Ekonomi pariwisata: introduksi, informasi, dan aplikasi. Jakarta: Penerbit Buku Kompas.

Zulpikar, F., Prasetiyo, D. E., Shelvatis, T. V., Komara, K. K., \& Pramudawardhani, M. (2017). Valuasi ekonomi objek wisata berbasis jasa lingkungan menggunakan metode biaya perjalanan di pantai batu karas kabupaten Pangandaran. Journal of Regional and Rural Development Planning, 1 , 1. doi:10.29244/jp2wd.2017.1.1.53-63

\section{BIODATA PENULIS}

Dr. Tatan Sukwika, M.Si sebagai dosen S-1 pada program studi Teknik Lingkungan dan dosen S-2 pada Magister Manajemen Universitas Sahid Jakarta.

Fitra Rahmatulloh, ST, sebagai alumnus S-1 dari program studi Teknik Lingkungan, Fakultas Teknik Universitas Sahid Jakarta. 